\title{
Adsorption of DDT and PCB Using Natural Soil and Carbon Nanotube
}

\author{
Mohd Raihan Taha, Shariat Mobassera \\ Dept of Civil \& Structural Engineering, Universiti Kebangsaan Malaysia, Bangi, Selangor, 43600, Malaysia
}

\begin{abstract}
Both DDT and PCB are amongst the contaminants quite often being release to the environment. They are not only carcinogen but also very persistent and being able to linger in the environment for a very long time. In addition, they are also very difficult to be cleaned up once once exposed or released to the environment. In this study, both of these contaminants were subjected to adsorption by natural soil carbon nanotube system. Batch adsorption studies were conducted evaluate the efficiency of a local residual soil with various amounts of multiwalled nanotube (MWNT) to adsorb DDT and PCB in solution. For each set of test, the adsorption equilibrium time was also determined. It was found that the equilibrium time for adsorption of both contaminants were about 22 and 49 hours, respectively for DDT and PCB. As expected, the amounts of the contaminants adsorbed increases as the MWNT contents were increased. The maximum percentage of adsorption were about 90 and $80 \%$, respectively for DDT and PCB for up to $10 \%$ of MWNT by weight of the original soil used. The results of the study were also analyzed with respect to the various adsorption isotherms, i.e. Freundlich, Langmuir, Temkin, and Redlich-Peterson. Linearized Langmuir adsorption isotherm showed the best fit for the experimental data for both systems while the linearized Redlich-Peterson was the least fit amongst the isotherms. In addition, it was also found that the linear form of the simple Temkin isotherm was able to fit all adsorption data quite well. Nevertheless all linearized isotherms tested showed sufficient capability to predict the data obtained.
\end{abstract}

Keywords: Adsorption; geoenvironment; nanomaterials; residual soil; Malaysia.

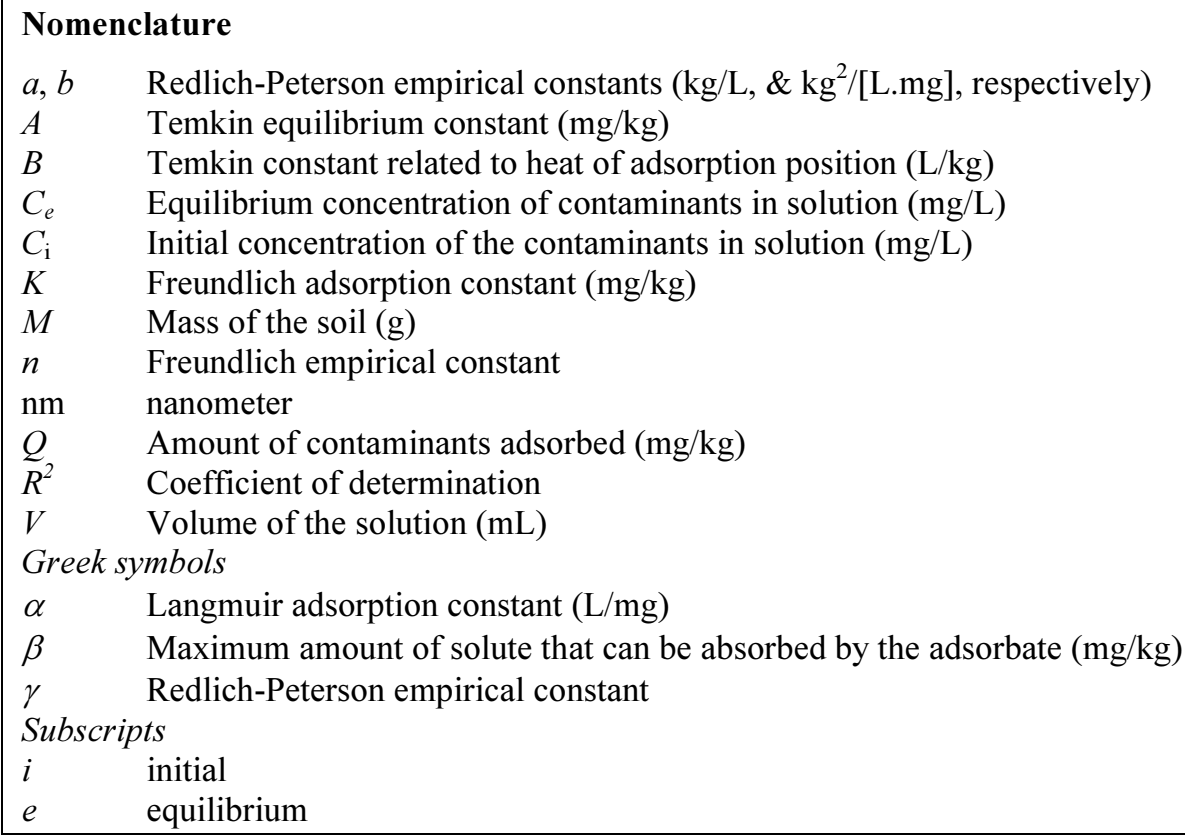

$a, b \quad$ Redlich-Peterson empirical constants ( $\mathrm{kg} / \mathrm{L}, \& \mathrm{~kg}^{2} /[\mathrm{L} \cdot \mathrm{mg}]$, respectively)

A Temkin equilibrium constant $(\mathrm{mg} / \mathrm{kg})$

$B \quad$ Temkin constant related to heat of adsorption position $(\mathrm{L} / \mathrm{kg})$

$C_{e} \quad$ Equilibrium concentration of contaminants in solution $(\mathrm{mg} / \mathrm{L})$

$C_{\mathrm{i}} \quad$ Initial concentration of the contaminants in solution $(\mathrm{mg} / \mathrm{L})$

$K \quad$ Freundlich adsorption constant $(\mathrm{mg} / \mathrm{kg})$

$M \quad$ Mass of the soil (g)

$n \quad$ Freundlich empirical constant

nm nanometer

$Q \quad$ Amount of contaminants adsorbed $(\mathrm{mg} / \mathrm{kg})$

$R^{2} \quad$ Coefficient of determination

$V \quad$ Volume of the solution $(\mathrm{mL})$

Greek symbols

$\alpha \quad$ Langmuir adsorption constant (L/mg)

$\beta \quad$ Maximum amount of solute that can be absorbed by the adsorbate $(\mathrm{mg} / \mathrm{kg})$

$\gamma \quad$ Redlich-Peterson empirical constant

Subscripts

$i$ initial

$e \quad$ equilibrium

Corresponding author: Mohd Raihan Taha. E-mail address: drmrt@eng.ukm.my

http://dx.doi.org/10.3846/enviro.2014.062

(C) 2014 The Authors. Published by VGTU Press. This is an open-access article distributed under the terms of the Creative Commons Attribution License, which permits unrestricted use, distribution, and reproduction in any medium, provided the original author and source are credited. 


\section{Introduction}

DDT (dichlorodiphenyltrichloroethane) and PCB (polychlorinated biphenyls) were much used in manufacturing and agriculture, respectively. Both these chemicals were banned in many countries due to its impact on human and wild life, and its top producer stopping production more than 30 years ago. Still much of DDT and PCB (polychlorinated biphenyls) still linger in the environment and was detected in many places [1]. Their persistence is very well known and much efforts will be required to remove them from the ecosystem [2].

Carbon nanotubes (CNTs) are very well known product of intense development in nanotechnology. It has found its use in all fields and being dubbed as "a solution looking for problems". CNTs are basically hollow, cylindrical in shape composed of a single sheet of carbon atoms, and have exceptional properties [3]. Generally, CNTs can be divided into single walled nanotube (SWNT) and multiple walled nanotube (MWNT). Due to ease of production and now available inexpensively, MWNT have found greater application and generated wide interest amongst researchers.

In this study, the application of MWNT for remediation of PCB and DDT in groundwater is evaluated by its adsorption behavior. Adsorption is one of the mechanisms for removal of contaminants using permeable reactive barrier (PRB) system as shown in Fig. 1 [4]. As the water passes the PRB (which consists typically of soil and additives, i.e. MWNT in this case), some of the the contaminants are absorbed on the PRB materials. Other contaminants could be degraded or reduced by the materials in the PRB. Immobilization of contaminants also incorporates adsorption as one of its mechanism as a decontamination process [5].

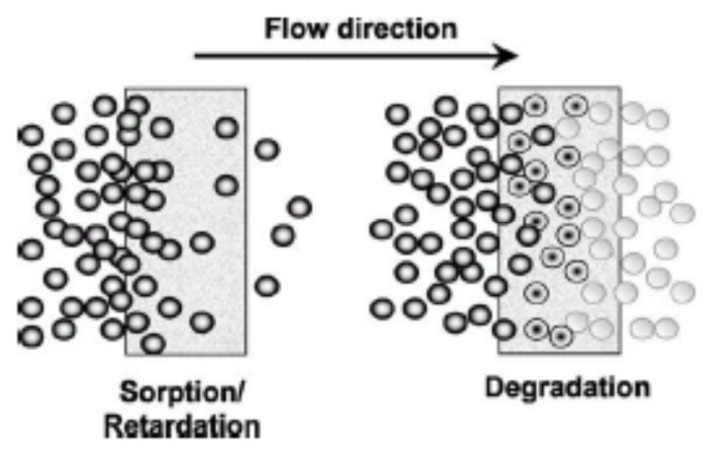

Fig. 1. Contaminant removal mechanisms in permeable reactive barrier [4]

\section{Materials and Methods}

The main adsorption material is a local residual soil and the purpose of MWNT is to possibly enhance adsorption the process by virtue of its large surface area. The type of soil used is not important but the use of soil with high fines contents (clayey soils) can be advantageous over granular soils as it can adsorbed greater amounts of contaminants due to its larger surface area. In addition, locally available materials can significantly reduce the overall construction cost of the remediation system. The soil was obtained with the campus of Universiti Kebangsaan Malaysia, in Bangi, Selangor, Malaysia. This type of soil, i.e. is widely distributed in Malaysia. It is one of the 2 residual soils which in total make up of more that $75 \%$ of Peninsular Malaysia. Some of the properties of the soil is shown in Table 1. The pH of soil is acidic and typical of soils in tropical regions where hot and humid climate with heavy rains causes much carbon dioxide in the atmosphere is transferred as carbonic acid to the soil rendering the soil low in $\mathrm{pH}$. The clay fraction of the soil is about $30 \%$, which can be considered as high.

Table 1. Some basic properties of soil

\begin{tabular}{ll}
\hline Property & Value \\
\hline Natural moisture content & $20.7 \%$ \\
$\mathrm{pH}\left(20^{\circ} \mathrm{C}\right)$ & 5.14 \\
Cation exchange capacity, CEC (meq $/ 100 \mathrm{~g})$ & 10.9 \\
Clay fraction $(<2 \mu \mathrm{m})$ & $29.6 \%$ \\
Unified Soil Classification System, USCS & $\mathrm{CL}$ \\
\hline
\end{tabular}

The carbon nanotube used in this study is a MWNT that was purchased from Arkema (France). It comes in black powdered form and light in appearance (maximum density less than half that of water). Some of the properties of the MWNT are given in Table 2.

The DDT and PCB representing the contaminants are specifically 4,4-DDT and 2-chlorobiphenyl, respectively, and both chemicals were purchased from Sigma Aldrich, USA. The batch adsorption tests was used in this study. The soil samples (with and without MWNT) were shaken with the contaminants in glass vials for 22 hours and 49 hours, respectively for 
DDT and PCB. The concentrations of contaminants were from 10 to $60 \mathrm{ppm}$ (60 mL volume), and the weight of MWNT added was up to $10 \%$ of the total weight of soil (12 g). After the shaking period, the samples were allowed to rest for a few minutes then the liquid and solid phases were filtered. Subsequently, the concentrations of DDT and PCB in the liquid were obtained by gas chromatography (Agilent 7890 A Series). All samples were tested in triplicates. The following equation [6] was used to calculate the amount of contaminants adsorbed $(Q)$ :

$$
Q=\left(C_{i}-C_{e}\right) \frac{V}{M}
$$

where $\mathrm{Ci}=$ the initial concentration of the contaminants $(\mathrm{mg} / \mathrm{L}) . \mathrm{Ce}=$ the final or equilibrium concentrations of the contaminants $(\mathrm{mg} / \mathrm{L}), V=$ the volume of the solution (fixed at $60 \mathrm{~mL}$ ), and $M=$ the mass of the soil (fixed at $12 \mathrm{~g}$ ).

Table 2. Some properties of MWNT used in this study

\begin{tabular}{ll}
\hline Property & Value \\
\hline Average diameter & $10-20 \mathrm{~nm}$ \\
Purity & $>90 \%$ \\
Average thickness & $0.2-0.4 \mathrm{~nm}$ \\
Total surface area & $1200 \mathrm{~m}^{2} / \mathrm{g}$ \\
Density & $50-400 \mathrm{~kg} / \mathrm{m}^{3}$ \\
\hline
\end{tabular}

Four well established adsorption isotherms were investigated to examine its usefulness in predicting adsorption characteristics. These include Freundlich, Langmuir, Temkin \& Redlich-Peterson (all linearized) and may be written respectively as

$$
\begin{gathered}
\ln Q=\ln K+\frac{1}{n} \ln C_{e} \\
\frac{1}{Q}=\frac{1}{\beta}+\frac{1}{\alpha \beta C_{e}} \\
Q=A+2.303 B \log C_{e} \\
\frac{C_{e}}{Q}=\frac{1}{a}+\frac{b}{a} C_{e}^{\gamma}
\end{gathered}
$$

In Eqns (2)-(5), $Q$ and $C_{e}$ were defined in Eqn (1), $K$ is the Freundlich adsorption constant, $n$ is an empirical constant measuring the favourability of adsorption, $\alpha$ is the Langmuir adsorption related to the binding energy or the 'affinity' parameter [7], $\beta$ is a parameter measuring the maximum amount of solute that can be adsorbed by the adsorbate (in this case, soil + MWNT), $A$ is the Temkin equilibrium constant, $B$ is a constant related to heat of adsorption, and $a, b$, and $\gamma$ are Redlich-Peterson empirical constants. Except for Redlich-Peterson's equation, all parameters can be easily predicted using linearized plots. In the case of Redlich-Peterson, the isotherm equation contains three unknown parameters. Therefore, a minimization procedure was adopted to maximize the coefficient of determination $R^{2}$ between the theoretical data for the $Q$ predicted from the linearized form of Redlich-Peterson isotherm equation and the experimental data. It must also be mentioned that the units of the parameters were strictly derived from the linearized plots. Other units can also be obtained from basic derivation of the isotherms and thus differ from that written in this paper.

\section{Results and Discussion}

Figure 2 shows the adsorption \% against time for DDT and soil-MWNT system at !0\% MWNT by weight of soil (12 g). Maximum adsorption of about $90 \%$ took place for $10 \mathrm{ppm}$ DDT solution after about 22 hours and became constant thereafter. The adsorption \% drops systematically with increase in DDT concentrations. For PCB (Fig. 3), the maximum adsorption was close to $80 \%$ at about 49 hours. Thus, it is more difficult and took longer to remove PCB compared to DDT through adsorption. It is also expected that PCB will linger in sediment much more prominently and over longer period of time than that of DDT. In addition, as mentioned earlier, the results of this series of test establishes the equilibrium time for analyses of DDT and PCB in the subsequent batch adsorption tests, i.e. 22 and 49 hours, respectively.

The adsorption percentage with respect to the weight of MWNT are shown in Figure 4 and 5. Obviously, the adsorption of DDT by MWNT is higher as more MWNT and greater surface area is available for adsorption (Fig. 4). Adsorption also becomes more difficult and challenging when more DDT is available leading to reducing percentage of adsorption as the dosage of DDT is increased from 10 to $60 \mathrm{ppm}$. Similar trend is observed for PCB series but the results are less obvious. As shown in Figure 5, the results for PCB shows little difference (though measurable) with respect to the weight of MWNT and 
PCB concentrations in general. The adsorption for 0.25 to $10 \%$ MWNT shows a narrow range of about $65-75 \%$ average adsorption for all PCB concentrations (10-60 ppm) tested in this study.

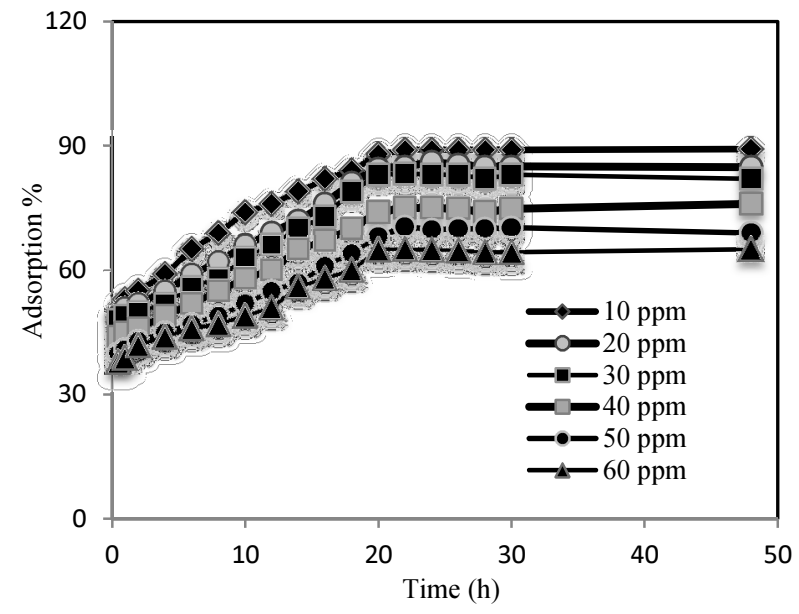

Fig. 2. Effect of contact time on DDT adsorption

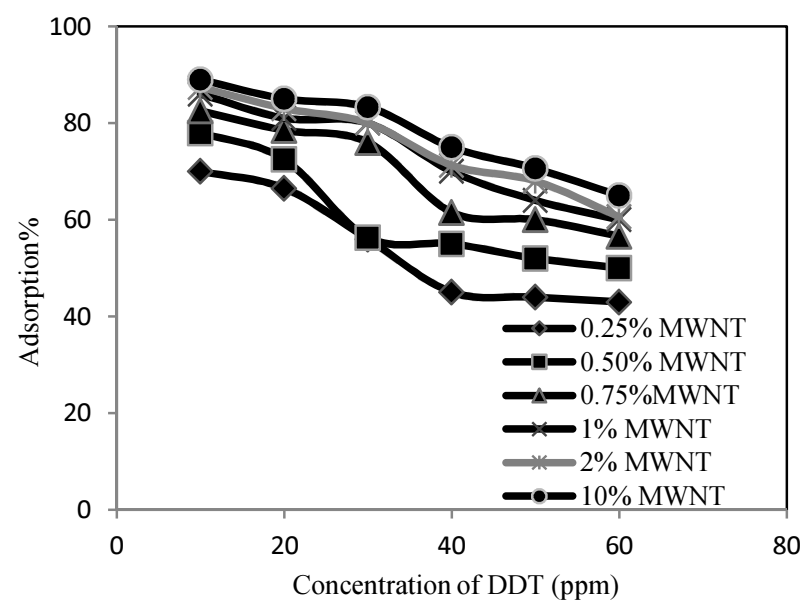

Fig. 4. DDT adsorption by various amount of MWNT

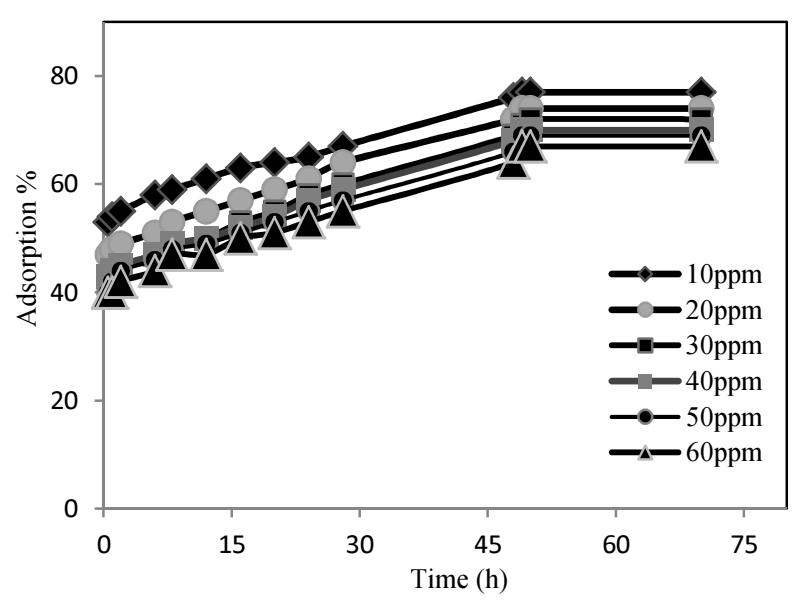

Fig. 3. Effect of contact time on PCB adsorption

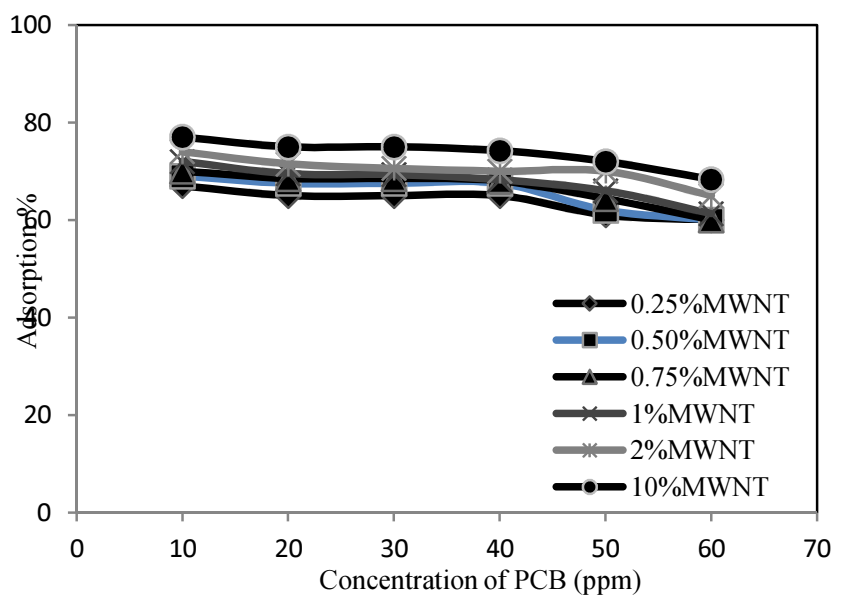

Fig. 5. PCB adsorption by various amount of MWNT

The traditional adsorption isotherm (plot of adsorption amount, $Q$, against equilibrium concentrations, $C_{e}$ ) are shown in Figure 6 and 7. In many solute/contaminant transport studies, this plot is assumed to be linear, yielding the slope $\left(Q / C_{e}\right)$ to be defined as the well known partition coefficient, $K_{d}$. This is generally true at low solute concentrations (dilute solutions) as demonstrated in the figures. Up to about $10 \mathrm{ppm}$ equilibrium concentration (for both cases), a straight line can be drawn to represent the partition coefficient. Beyond $10 \mathrm{ppm}$, especially at much higher concentrations, a curvilinear plot evolves. Physically, this means that at low solute concentrations, the solute available is absorbed by the soil-MWNT system directly proportional to the available surface area. As the available sorption sites are being used up, less is available for sorption. Thus, adsorption decreases and as a result, non-linearity of the plot is established. In this study, the non-linearity of the plot is more significant in the case of DDT compared to PCB.

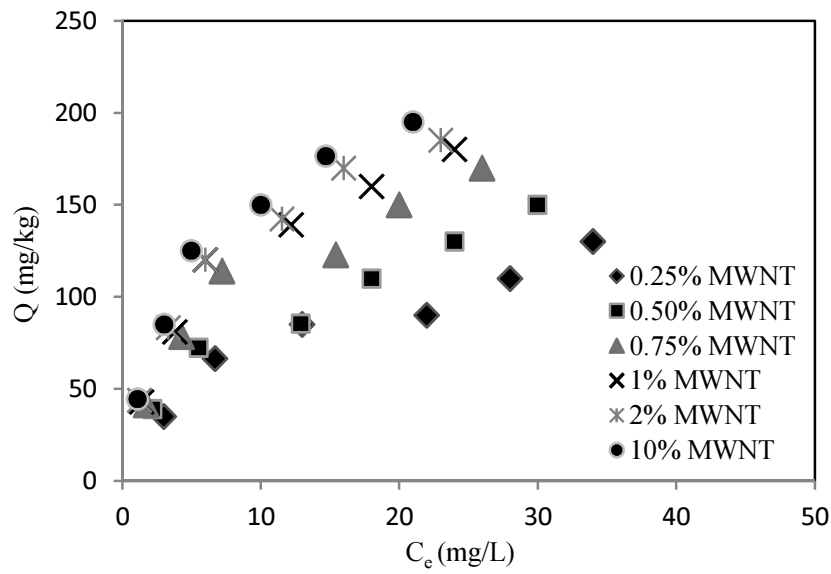

Fig. 6. Adsorption isotherm for DDT onto soil-MWNT

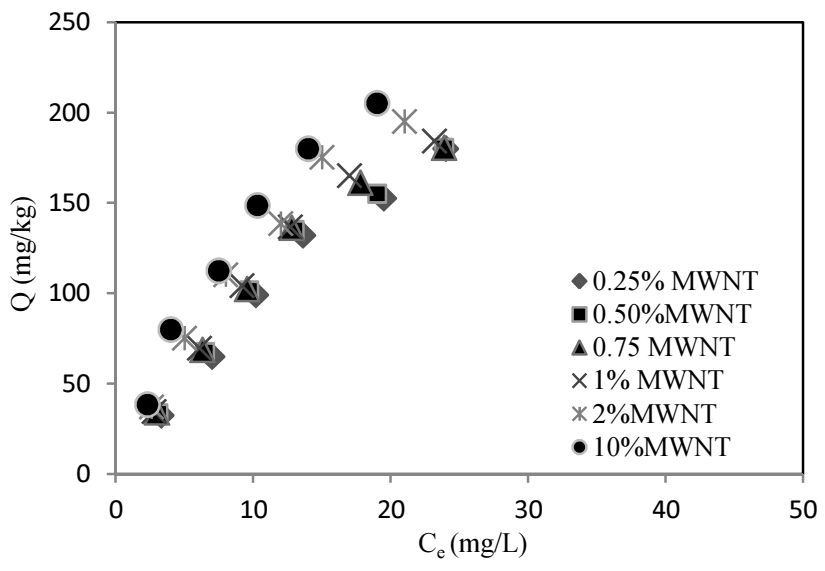

Fig. 7. Adsorption isotherm for PCB onto soil-MWNT 
Many adsorption models are available to describe adsorption-desorption behavior of adsorbate-adsorbent system. These models contained many parameters and one of the easiest and arguable powerful methods to obtain these parameters is by linearizing the equation. As such, a linear plot can be drawn and the parameters can be easily estimated from these plots.

From the results of this study, the linearized plots of $\operatorname{Ln} Q$ vs $\operatorname{Ln} C_{e}, 1 / Q$ vs $1 / C_{e}, Q$ vs $\log C_{e}$, and $C_{e} / Q$ vs $C_{e}$. were made for Freundlich, Langmuir, Temkin, and Redlich-Peterson isotherms, respectively. These are shown in Figures 8 to 15 and the parameters for the models are summarised in Table 3. Figures 8 to 15 indicates that in majority of cases a straight line can be drawn for the data in the tests results with a good coefficient of determination (minimum $R^{2}$ is 0.8 for Redlich Peterson isotherm). For Freundlich model (the first published adsorption model), the model was shown to theoretically superior for the prediction of mainly metallic ions [8]. The linearized model (Figs 8 and 9) for fitting the data obtained from this study also yielded excellent $R^{2}$ (i.e. 0.96 and 0.96 for DDT and PCB, respectively). The value of $n$ is normally used for discussion as it indicates whether adsorption is favourable (good) or unfavorable (poor). It is generally stated that values of $n$ in the range 2-10 represent good, 1-2 moderately difficult, and less than 1 poor adsorption characteristics [9], [10]. The $n$ value for DDT shows favourable while moderately difficult for PCB. This may also have been depicted in the equilibrium times discussed earlier in which it was 22 hours for DDT and 49 hours for PCB. In addition, $n$ values greater than 1 also serve show that the adsorption involved is physical instead of chemical process [11].

From linearized Langmuir model (Figs 10 and 11), it was found that the $\beta$ value (maximum amount of solute/contaminant adsorbed) was higher for PCB compared to DDT. This indicates that PCB is adsorbed much more on the soil or sediments compared to DDT. Thus PCB will also linger a lot longer in the environment with slow rate of release and the desorption of PCB is also generally very difficult even with enhanced procedures [12]. The simplistic linearized Temkin isotherm (Figs 11 and 12) also showed excellent fitting to the obtained adsorption data. The Redlich-Peterson linearized isotherm (Figs 13 and 14) showed the lowest $R^{2}$ involving PCB data but still overall good fitting at $R^{2}$ of 0.8 .

In general, the parameters of all the models actually provided insight into mode of adsorption, the binding energy and heat of adsorption. However, in this paper these details are not discussed as it is aimed at finding reliable models to describe the adsorption data in addition to evaluating the suitability of the adsorbent material, i.e. soil + MWNT.

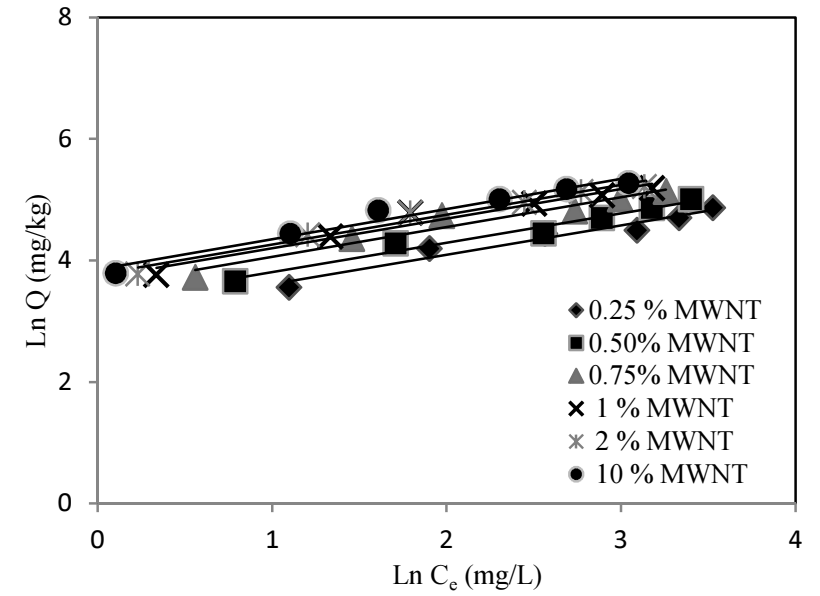

Fig. 8. Linearized Freundlich adsorption isotherm for DDT onto soil-MWNT

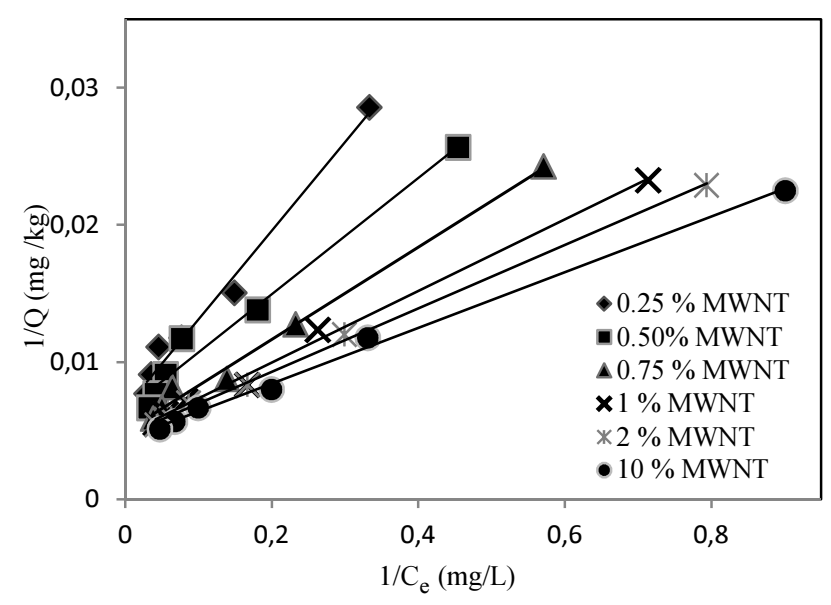

Fig. 10. Linearized Langmuir adsorption isotherm for DDT onto soil-MWNT

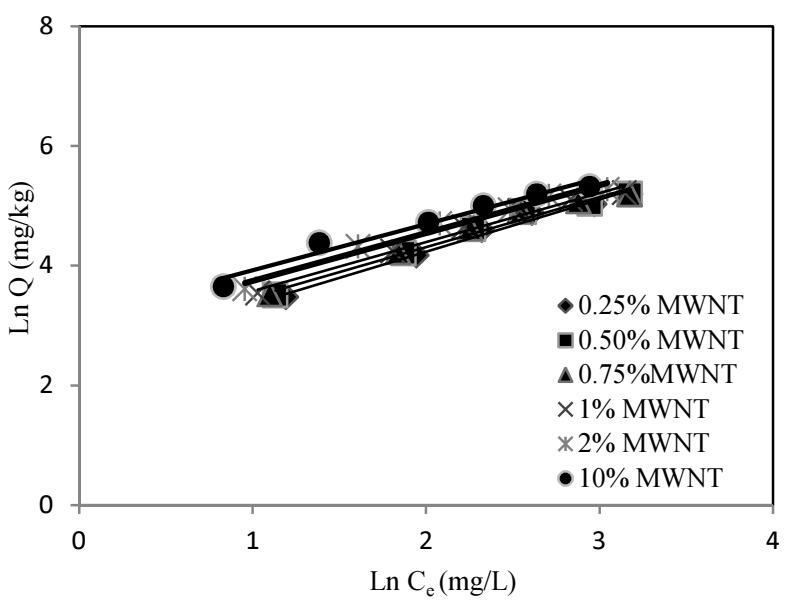

Fig. 9. Linearized Freundlich adsorption isotherm for PCB onto soil-MWNT

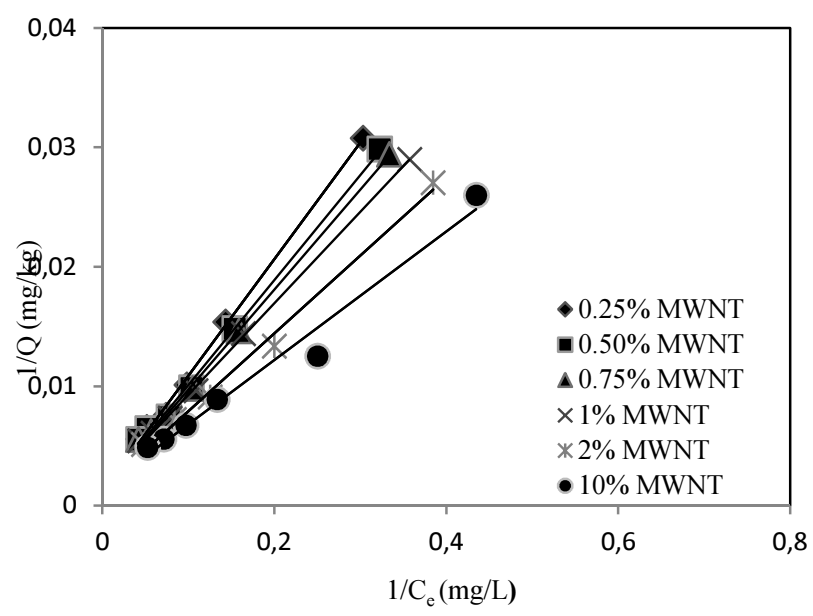

Fig. 11. Linearized Langmuir adsorption isotherm for PCB onto soil-MWNT 


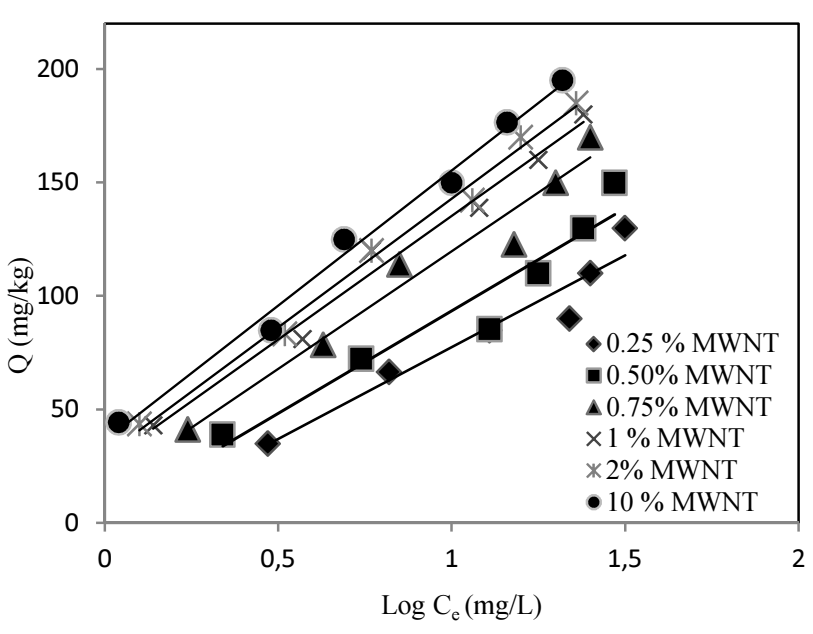

Fig. 12. Linearized Temkin adsorption isotherm for DDT onto soil-MWNT

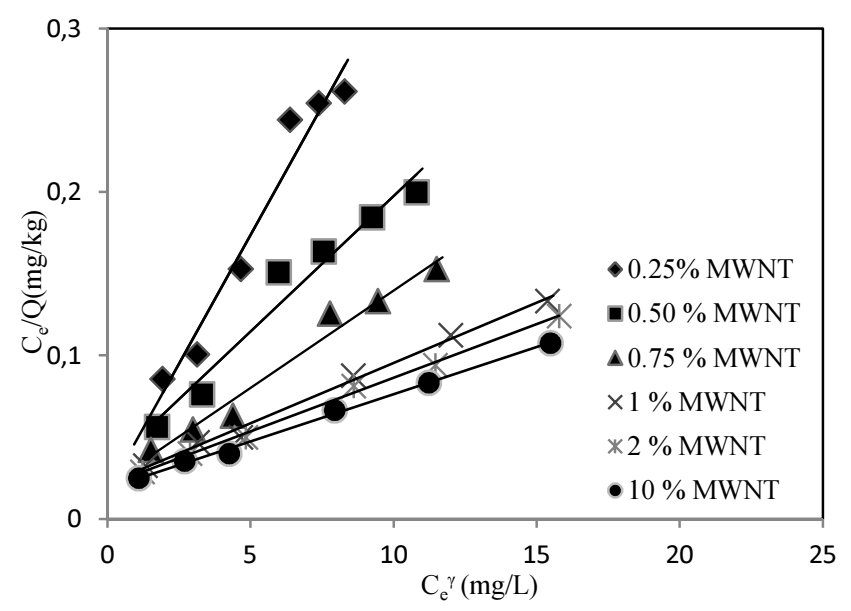

Fig. 14. Linearized Redlich-Peterson adsorption isotherm for DDT onto soil-MWNT

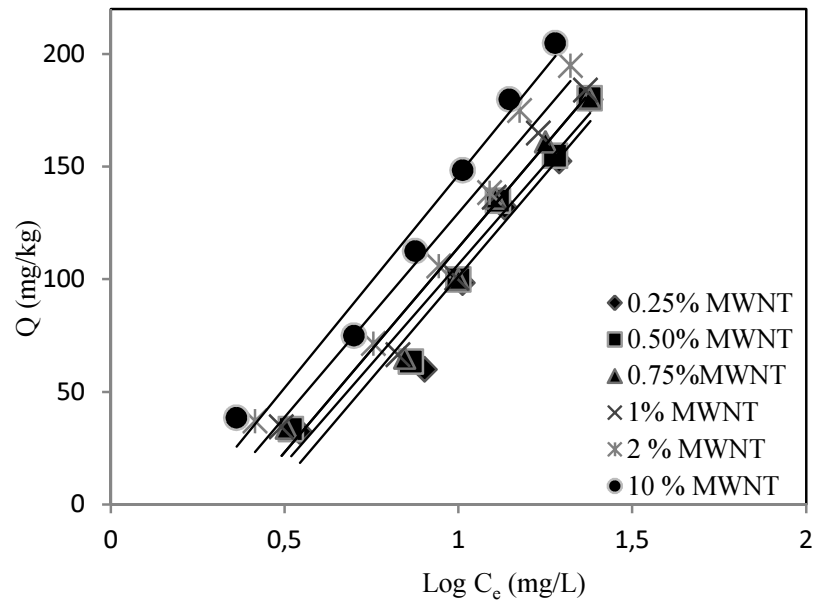

Fig. 13. Linearized Temkin adsorption isotherm for PCB onto soil-MWNT

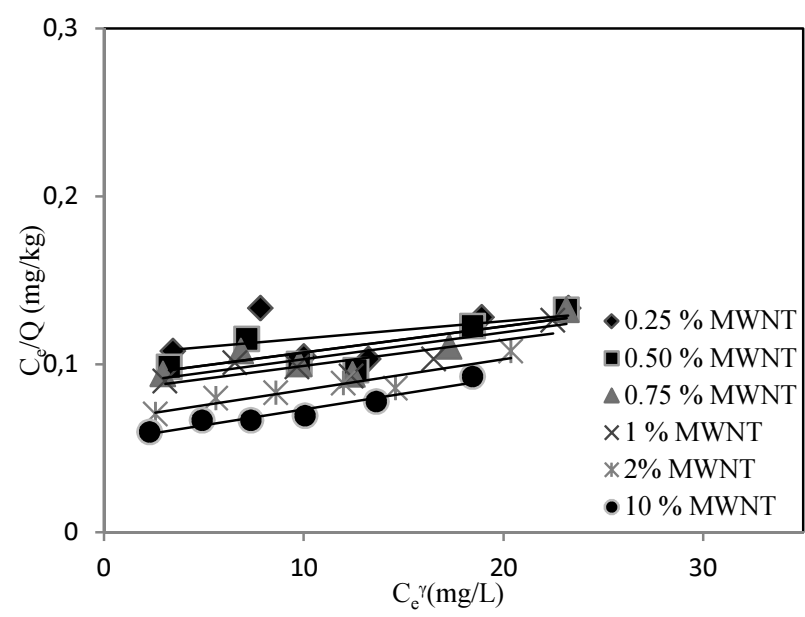

Fig. 15. Linearized Redlich-Peterson adsorption isotherm for PCB onto soil-MWNT

Table 3. Summary of linearized adsorption model parameters

\begin{tabular}{|c|c|c|c|}
\hline Linearized Models & & Parameters & $R^{2}$ \\
\hline \multirow[b]{2}{*}{ Freundlich } & DDT & $\begin{array}{l}K=36.1 \mathrm{mg} / \mathrm{g} \\
n=2.06\end{array}$ & 0.96 \\
\hline & PCB & $\begin{array}{l}K=16.44 \mathrm{mg} / \mathrm{g} \\
n=1.2\end{array}$ & 0.97 \\
\hline \multirow{2}{*}{ Langmuir } & DDT & $\begin{array}{l}\alpha=0.16 \\
\beta=197.23 \mathrm{mg} / \mathrm{g}\end{array}$ & 0.99 \\
\hline & PCB & $\begin{array}{l}\alpha=0.187 \\
\beta=712.5 \mathrm{mg} / \mathrm{g}\end{array}$ & 0.99 \\
\hline \multirow{2}{*}{ Temkin } & DDT & $\begin{array}{l}a=19.1 \mathrm{~L} / \mathrm{mg} \\
b=44.54\end{array}$ & 0.96 \\
\hline & PCB & $\begin{array}{l}a=-63.5 \mathrm{~L} / \mathrm{mg} \\
b=78.76\end{array}$ & 0.95 \\
\hline \multirow{2}{*}{$\begin{array}{l}\text { Redlich- } \\
\text { Peterson }\end{array}$} & DDT & $\begin{array}{l}A=107.45 \\
B=7.13, \gamma=0.828\end{array}$ & 0.97 \\
\hline & PCB & $\begin{array}{l}A=13.15 \\
B=0.22, \gamma=0.995\end{array}$ & 0.80 \\
\hline
\end{tabular}




\section{Conclusions}

Batch adsorption tests were conducted to evaluate the suitability of soil - carbon nanotube matrix as a material for permeable reactive barrier system for remediation of DDT and PCB. The soil used is a local residual soil and the carbon nanotube is a multiwalled nanotube, (MWNT). The concentrations of DDT and PCB used were from $10 \mathrm{ppm}$ to $60 \mathrm{ppm}$. The results of the study indicated that a maximum of more than $90 \%$ and almost $80 \%$ of DDT and PCB, respectively was removed from solution. The capacity of adsorption increases as the amount of MWNT increases and decreases as the concentrations of DDT and PCB increases. It is also found that a simple linearized form of Temkin adsorption isotherm can sufficiently describe the adsorption data with high coefficient of determination. Other tested linearized isotherms (Freundlich, Langmuir and Redlich-Peterson) are also equally well suited to fit the adsorption data obtained in this study.

\section{References}

[1] Bineli, A.; Provini, A. 2003. DDT is still a problem in developed countries: the heavy pollution of Lake Maggiore, Chemosphere 52: 717-723. http://dx.doi.org/10.1016/S0045-6535(03)00188-7

[2] Sudharshan, S.; Naidu, R.; Mallavarapu, M.; Bolan, N. 2012. DDT remediation in contaminated soil: a review of recent studies, Biodegradation 23(6): 851-863. http://dx.doi.org/10.1007/s10532-012-9575-4

[3] Shulaker, M. M.; Hills, G., Patil, N.; Wei, H.; Chen, H.Y.; Wong, H.S.P.; Mitra, S. 2013. Carbon nanotube computer, Nature 51: $526-536$. http://dx.doi.org/10.1038/nature12502

[4] Bowman, R. S. 2003. Applications of surfactant-modified zeolites to environmental remediation, Microporous and Mesoporous Materials 61: 43-56. http://dx.doi.org/10.1016/S1387-1811(03)00354-8

[5] Zhang, W. X. 2003. Nanoscale iron particles for environmental remediation: An overview, Journal of Nanoparticle Research (5): 323-332. Kluwer Academic Publishers, Netherlands.

[6] Taha, M. R.; Leng, T. O.; Mohamad, A. B.; Kadhum, A. A. H. 2003. Batch adsorption tests of phenol in soils, Bull Eng Geol Env 62: 251-257. http://dx.doi.org/10.1007/s10064-002-0181-2

[7] Veith, J.A.; Sposito, G. 1997. On the use of Langmuir equation in the imterpretation of adsorption phenomena, J. Am Soil Sci Soc 41:697-702. http://dx.doi.org/10.2136/sssaj1977.03615995004100040015x

[8] Nakahara, O. 1996. Reconsideration of theoretical basis of Freundlich adsorption isotherm equation, Soil Science and Plant Nutrition 42(1): 51-61. http://dx.doi.org/10.1080/00380768.1996.10414688

[9] Treybal, R. E. 1980. Mass-Transfer Operations, 3rd ed., McGraw-Hill, 784 p.

[10] Hamdaoui, O.; Naffrechoux, E. 2007. Modeling of adsorption isotherms of phenol and chlorophenols onto granular activated carbon - Part I. Twoparameter models and equations allowing determination of thermodynamic parameters, J. Hazardous Materials 147: $381-394$. http://dx.doi.org/10.1016/j.jhazmat.2007.01.021

[11] Desta, M. B. 2013. Batch sorption experiments: Langmuir and Freundlich isotherm studies for the adsorption of textile metal ions onto teff straw (Eragrostis tef) agricultural waste, Journal of Thermodynamics, Hindawi Pub Co, Volume 2013, Article ID 375830,6 pp.

[12] Cao, M.; Hu, Y.; Sun, Q.; Wang, L.; Chen, J.; Lu, X. 2013. Enhanced desorption of PCB and trace metal elements (Pb and Cu) from contaminated soils by saponin and EDDS mixed solution, Environmental Pollution 174: 93-99. http://dx.doi.org/10.1016/j.envpol.2012.11.015 